\title{
El des-financiamiento de las políticas sociales, el Banco Central como prestamista del fisco y el fracaso del modelo desarrollista (Chile, 1932-1955)
}

The de-financing of the social policies, the central bank as a lender of the State and the failure of the developer model (Chile, 1932-1955)

Mauricio Casanova*

\section{RESUMEN}

El presente artículo analiza las consecuencias inesperadas del financiamiento de las políticas ISI en Chile: el des-financiamiento de las políticas sociales, la necesidad de recurrir a los créditos del Banco Central para evitar el déficit fiscal y el resurgimiento de un grave proceso inflacionario. Las conclusiones de esta investigación sugieren que las principales aproximaciones historiográficas sobre este periodo (basadas en una supuesta relación entre el aumento del estándar de vida y el proceso de industrialización) necesitan ser repensadas.

Palabras claves: Chile, modelo ISI, Banco Central de Chile, políticas sociales

\section{ABSTRACT}

In this article, the unexpected consequences of the financing of ISI policies in Chile: the under-financing of social policies, the need to resort the credits of the Central Bank to avoid fiscal deficit, and the resurgence of an acute inflationary cycle are analyzed. The conclusions of this research suggest that the main historiographical approaches on this period (based on an alleged relations between the increase on living standard and the industrialization process) need a radical rethink.

Keywords: Chile, ISI model, Central Bank of Chile, social policies

Recibido: noviembre 2018

Aceptado: diciembre 2018

\section{Introducción}

En los últimos años, la relación entre industrialización y estándar de vida ha estado en el centro de un intenso debate historiográfico. La renovación del clásico debate en torno a los orígenes de la gran divergencia entre occidente y el resto del mundo, que ha causado alto impacto en la

\footnotetext{
* Magíster en Filosofía por la Universidad de Chile y PhD en Historia Contemporánea por la Freie Universität Berlin. Especializado en teoría de la historia e historia económica. Email: m.casanovabrito@gmail.com.
} 
literatura, es un reflejo de esta situación ${ }^{1}$. Mientras que ciertos historiadores sostienen que los altos salarios y el acceso al carbón fueron las bases del take-off industrial en el norte de Europa ${ }^{2}$, otros ponen en duda esta tesis y afirman que, en otras zonas geográficas (como China, Japón o incluso la India) los salarios no eran tan diferentes ${ }^{3}$. Para este segundo grupo de historiadores, el costo de la mano de obra no es una razón suficiente para explicar el origen histórico de la divergencia. La clave, en cambio, habría estado en los denominados factores ecológicos: la incorporación a la dieta de productos foráneos (té, azúcar, café, tabaco, maíz, etc.), lo que habría permitido re-direccionar el tiempo de trabajo de la economía doméstica hacia labores noagrícolas, sin necesidad de expandir la tierra cultivable o la mano de obra.

Para el caso de Chile, la literatura también suele establecer un vínculo directo entre industrialización e incremento del estándar de vida durante el periodo ISI. La tesis del Estado de compromiso suele ser preponderante al momento de examinar esta relación ${ }^{4}$. Según esta, los salarios reales habrían aumentado en el periodo 1932-1955 debido a la implementación de un

${ }^{1}$ Gupta, Bishnupriya y Ma, Debin. "Europe in an Asian mirror: The Great Divergence" en H. O'Rourke, Kevin y Broadberry, Stephen (eds.). 2010. The Cambridge Economic History of Modern Europe: Volume 1: 1700-1870, Cambridge, Cambridge University Press, pp. 264-285; Vries, Peer. 2010. "The California School and Beyond: How to Study the Great Divergence?" en History Compass 8, pp. 730-751; Coclanis, Peter A. 2011. "Ten Years After: Reflections on Kenneth Pomeranz's The Great Divergence" en Historically Speaking 12, pp. 10-12; Prechtl, Susanne. "Ressourcen der Neuen Welt und englische Kohle als Schlüsselfaktoren westeuropäischer Dominanz: The Great Divergence von Kenneth Pomeranz", en Sebaldt, Martin; Friedel, Sabine; Fütterer, Andreas; Schmid, Sarah(eds.). 2016. Aufstieg und Fall westlicher Herrschaft: Zum Grundproblem globaler Politik im Spiegel moderner Klassiker, Wiesbaden, Springer Fachmedien Wiesbaden, pp. 97-118; Middell, Matthias y Robinson, Philipp. 2016. "The Great Divergence Debate" en Comparativ, vol. 26 (3), pp. 7-24; Beckert, Sven y Sachsenmaier, Dominic (eds.). 2018. Global History, Globally: Research and Practice around the World, London, Bloomsbury Publishing.

${ }^{2}$ Allen, Robert; Bengtsso, Tommy; Dribe, Martin. 2005. Living Standards in the Past: New Perspectives on Well-Being in Asia and Europe. Oxford OUP Oxford; Broadberry, Stephen y Gupta, Bishnupriya. 2006. "The early modern great divergence: wages, prices and economic development in Europe and Asia, 1500-1800" en The Economic History Review 59, pp. 2-31; Allen, Robert. 2009. The British industrial revolution in global perspective, Cambridge, Cambridge University Press; Allen, Robert. 2011. Global Economic History: A Very Short Introduction, Oxford, OUP Oxford.

${ }^{3}$ Pomeranz, Kenneth. 2000. The Great Divergence: China, Europe, and the Making of the Modern World Economy, New Jersey, Princeton University Press; Marks, Robert. 2007. The Origins of the Modern World: A Global and Ecological Narrative from the Fifteenth to the Twenty-first Century, United States, Rowman \& Littlefield Publishers; Goldstone, Jack. 2008. Why Europe? The Rise of the West in World History 1500-1850 New York, McGraw-Hill Education; Perdue, Peter. 2009. China Marches West: The Qing Conquest of Central Eurasia, United States, Harvard University Press; Rosenthal, Jean-Laurentand y Wong, Roy Bin. 2011. Before and beyond divergence: the politics of economic change in China and Europe, Cambridge, Harvard University Press; Glahn, Richard von. 2016. The Economic History of China: From Antiquity to the Nineteenth Century, Cambridge, Cambridge University Press.

${ }^{4}$ David Clark, Timothy. 2013. The State and the Making of Capitalist Modernity in Chile, York University, Tesis para optar al grado de doctor. 
modelo desarrollista ${ }^{5}$, caracterizado por programas de industrialización a largo plazo ${ }^{6}$, la expansión de las políticas sociales ${ }^{7}$ y la cooperación entre partidos de centro-izquierda, gremios empresariales, la burocracia técnica y los institutos científicos ${ }^{8}$. La supuesta mejora del estándar de vida de los trabajadores habría sido entonces el resultado de un Estado concebido como una instancia de conciliación de intereses entre actores sociales de diversa procedencia ${ }^{9}$. En un artículo publicado recientemente, se resume esta tesis de la siguiente manera:

"El modelo de desarrollo basado en la industrialización, se asoció a objetivos como la modernización institucional y la transformación social. Mejorar las condiciones de vida era necesario no tan solo desde un punto de vista humanitario, sino también era una tarea fundamental para generar el capital humano requerido por el nuevo modelo de desarrollo. Para ello se puso en marcha una nutrida gama de políticas sociales que buscaban cumplir con este objetivo. Sus resultados saltan a la vista y son fácilmente comprobables en los indicadores de desarrollo económico y social" 10 .

El objetivo del presente artículo es formular una interpretación histórica distinta. Nuestra hipótesis se basa en los siguientes puntos:

- Primero, que las políticas ISI eran financiadas y gestionadas de forma distinta a las políticas sociales. Las primeras estaban financiadas mediante empréstitos externos costeados con impuestos a las ganancias de las empresas extractoras de cobre, y administradas por

\footnotetext{
${ }^{5}$ Rodríguez, Javier. 2014. La economía política de la desigualdad de ingreso en Chile: 1850-2009, Universidad de la República, Tesis para optar el grado de doctor; Durán, Gonzalo. "Desigualdad y salarios en perspectiva histórica, siglos XIX y XX" en Jacksic, Iván; Robles, Claudio; Estefane, Andrés (eds.). 2018. Historia política de Chile, 1810-2010. Tomo III. Problemas económicos, Santiago de Chile, Fondo de Cultura Económica, pp. 239-278.

${ }^{6}$ Ortega, Luis, "La economía política de la industrialización a través de un siglo", en Jacksic, Iván; Robles, Claudio; Estefane, Andrés (eds.). 2018. Historia política de Chile, 1810-2010. Tomo III. Problemas económicos (Santiago, 2018), pp. 141-170.

7 Rengifo, Francisca, "El Estado de seguridad social chileno y la institucionalización desigual del bienestar" en Jaksic, Iván y Rengifo, Francisca (eds.). 2017. Historia política de Chile, 1810-2010. Tomo Il. Estado y sociedad, Santiago, Fondo de Cultura Económica, pp. 397-424; Vergara, Ángela. "Estado, trabajo y trabajadores" en Jaksic, Iván y Rengifo, Francisca (eds.). 2017. Historia política de Chile, 1810-2010. Tomo Il. Estado y sociedad, Santiago, Fondo de Cultura Económica, pp. 365-396.

${ }^{8}$ Cavarozzi, Marcelo. 1977. The government and the industrial bourgeoisie in Chile, 1938-1964, University of California, Tesis para optar al grado de doctor; Ibáñez, Adolfo. 2003. Herido en el ala: Estado, oligarquias, y subdesarrollo Chile 1924-1960, Santiago de Chile, Universidad Andrés Bello; Silva, Patricio. 2008. In the Name of Reason: Technocrats and Politics in Chile, Philadelphia, Pennsylvania State University Press.

${ }^{9}$ Moulian, Tomás. 1981. Desarrollo político y estado de compromiso: desajustes y crisis estatal en Chile, Santiago, Corporación de Investigaciones Económicas para Latinoamericana; Garreton, Manuel. 1983. El proceso polıtico chileno, Santiago de Chile, FLACSO; Montero, Cecilia. 1997. La revolución empresarial chilena, Santiago de Chile, CIEPLAN/Dolmen Ediciones; Gárate, Manuel. 2014. La revolución capitalista de Chile: 1973-2003, Santiago de Chile, Universidad Alberto Hurtado.

${ }^{10}$ Rivero, Rodrigo. 2018. "El crecimiento de la fecundidad frente a la modernización económica y las políticas sociales, Chile 1930-1973" en Revista de Gestión Pública, VII, p. 34.
} 
organismos corporativos (como la CORFO), en los que la injerencia de los gremios empresariales era significativa. Las segundas estaban financiadas con impuestos menores a corto plazo o prórrogas tributarias y eran gestionadas por los gobiernos de turno, los que tuvieron que enfrentar con frecuencia la oposición parlamentaria.

- Segundo, que esta escisión entre dos sub-regímenes de las políticas estatales condujo al desfinanciamiento de las políticas sociales. Esta situación, a su vez, forzó a los gobiernos de turno a recurrir a los créditos del Banco Central para confrontar el déficit público.

- Tercero, que esta tendencia de recurrir a la emisión de circulante del Banco Central provocó un grave ciclo inflacionario, el que afectó sobre todo a trabajadores informales urbanos y trabajadores agrícolas.

En esta investigación se sugiere que la relación entre el incremento del estándar de vida de los trabajadores y el modelo desarrollista debe ser revisada. Si bien los obreros industriales, de la construcción, de la industria de la energía o los trabajadores públicos efectivamente se vieron favorecidos por las reformas de los gobiernos de centro-izquierda, como muestran investigaciones recientes ${ }^{11}$, la situación no fue la misma para trabajadores informales o agrícolas; los que constituían la mayor parte de la fuerza de trabajo activa.

El artículo comienza con un análisis del financiamiento y la administración de las políticas de industrialización. La idea es mostrar que, desde la década de 1930, se estructuró un sistema en el que, por presión de los gremios empresariales, se aseguraba que la incidencia del poder ejecutivo en los fondos públicos destinados al fomento económico fuese lo más reducida posible. Luego se examinan las consecuencias de este sistema, a saber, el des-financiamiento de las políticas sociales y la necesidad de recurrir a los créditos del Banco Central para evitar el déficit fiscal. Finalmente, se muestra el impacto de estos créditos en el costo de la vida y el ingreso de los trabajadores.

\section{Financiamiento y administración de las políticas de industrialización}

Existe consenso tanto en la historiografía como en las ciencias sociales en torno al supuesto carácter estatista del modelo instaurado con posterioridad a la crisis internacional de 1929; el que se habría manifestado plenamente con los gobiernos radicales en el periodo 1938-1952. Sin embargo, la revisión detallada de las fuentes del periodo pone en cuestión la utilización de este concepto. En primer lugar, se debe considerar que si bien la CORFO, institución insigne del periodo desarrollista, era una persona jurídica de derecho público, sus estatutos garantizaban plenamente la inclusión de actores no-estatales en su administración. En las discusiones en el Congreso, las voces de los gremios empresariales manifestaron constantemente sus aprensiones

11 Rodríguez, Javier. 2014. La economía política de la desigualdad de ingreso en Chile; Durán, Gonzalo. 2018. "Desigualdad y salarios en perspectiva histórica, siglos XIX y XX". 
frente al carácter estatal de la corporación, prefiriendo una entidad corporativa en la que la gestión estuviese a cargo de ciertos ministros de Estado, parlamentarios, gremios empresariales e institutos técnico-científicos ${ }^{12}$.

Desde la década de 1930, las diversas voces del empresariado venían solicitando la creación de una entidad público-privada, formada por representantes estales y del mundo privado empresarial, que administrase, de forma técnica y des-politizada, los recursos públicos destinados al fomento de la economía ${ }^{13}$. A esta propuesta se le denominó en un principio Consejo de Economía Nacional; y fue la base para la elaboración del proyecto que creó la CORFO ${ }^{14}$. Se entendía que un consejo de este tipo sería:

"una garantía de competencia en el manejo de los fondos públicos y que ofrezcan la seguridad de un predominio de ideas económicas sobre las de carácter político. La certidumbre de que se realice lo último la proporciona desde luego la reducción de la representación fiscal y el aumento de la perteneciente a las entidades productoras y comerciales" 15

De hecho, la oposición al corporativismo, así como la defensa de un rol exclusivo del Estado en la administración de los fondos destinados a las políticas ISI no provenía solamente de ciertos sectores de la izquierda. En la discusión parlamentaria en torno a la creación de la CORFO, fue el partido conservador el que manifestó con mayor ímpetu sus aprensiones frente a posibles atisbos anti-constitucionales de la corporación. Para algunos parlamentarios conservadores no era aceptable que a la corporación "se le concedan facultades que la Constitución otorga privativamente al Senado, o más ampliamente, al Poder legislativo"16. Además, consideraban que no era posible otorgar financiamiento estatal a una entidad encargada de llevar a cabo un plan de fomento que al momento de la discusión parlamentaria no estaba concretado:

"absurdo y contrario al simple sentido común contratar enormes empréstitos para desarrollar un plan de fomento que no se conoce, un plan de fomento que se va a empezar a estudiar por la Corporación que crea esta ley [...] el congreso va a entregar la distribución de mil millones

\footnotetext{
12 Muñoz, Oscar y Arriagada, Ana María. 1977. Orígenes políticos y económicos del estado empresarial en Chile, Santiago, Corporación de Investigaciones Económicas para Latinoamérica; Ortega, Luis. 1989. Corporación de Fomento de la Producción: 50 años de realizaciones 1939-1989, Santiago, USACH, Facultad de Humanidades, Dept. de Historia. 13 Ibáñez, Adolfo. 1983. "Los ingenieros, el estado y la política en Chile. Del ministerio de fomento a la Corporación de Fomento de la Producción" en Historia, 18, pp. 45-102; Ibáñez, Adolfo. 1994. "El liderazgo en los gremios empresariales y su contribución al desarrollo del Estado Moderno durante la década del treinta: el fomento a la producción y los antecedentes de CORFO" en Historia, 28, pp. 183-216.

${ }^{14}$ Casanova, Mauricio. 2019. "La centro-izquierda, el corporativismo empresarial y las contradicciones internas del Estado desarrollista en Chile, 1932-1954" en Izquierdas, 48, pp. 190-210.

15 "El industrial", Sociedad de Fomento Fabril, febrero de 1939, p. 83.

16 Congreso Nacional de Chile, Cámara de Senadores. 1939. Sesiones extraordinarias, 29 de marzo de 1939, Santiago, p. 511.
} 
de pesos sin saber en qué objetos van a ser invertidos, lo que es inconstitucional o inaceptable"17.

Desde mediados de la década de 1920, la intervención del Estado en la economía venía siendo entendida como la participación de representantes tanto del parlamento como del poder ejecutivo en instituciones cuyos directorios incluían la presencia de representantes de las asociaciones empresariales (como la Sociedad de Fomento Fabril) o de instituciones científicas (como el Instituto de Ingenieros de la Universidad de Chile). Bajo este modelo de equilibrio de poderes fueron instaurados los diversos mecanismos semi-estatales de fomento económico, como la Caja de Crédito Agrario, el Instituto de Crédito Industrial o la Caja de Crédito Minero ${ }^{18}$. En la ley orgánica del Banco Central, creado en 1925, se reservó de igual manera un puesto en el directorio para los gremios empresariales, como la Sociedad de Fomento Fabril (SOFOFA), la Sociedad Nacional de Agricultura (SNA) o la Sociedad Nacional de Minería (SONAMI) ${ }^{19}$. Solamente en la República Socialista, a mediados de 1932, se crearon entidades gestionadas en su totalidad por actores estatales, como la Compañía Minera del Estado o la Compañía Industrial del Estado ${ }^{20}$; ambas disueltas cuando Arturo Alessandri vuelve al poder a finales de 1932.

Sin embargo, en la práctica, la incidencia real de los representantes de los poderes del Estado era dudosa. Los mismos ministros que ocupaban cargos en las instituciones semi-estatales de política-económica y encargados de representar la voz del ejecutivo, eran a su vez miembros de las principales asociaciones empresariales del país o mantenían vínculos directos e indirectos con las empresas favorecidas con recursos públicos ${ }^{21}$. La Empresa Nacional de Electricidad, por ejemplo, nace como un proyecto, propuesto por el ejecutivo, de una compañía controlada directamente por el Estado. No obstante, debido a la oposición de la misma CORFO, termina convirtiéndose en una sociedad anónima en la que la representación de los actores estatales estaba presente a través de la CORFO, para velar por la autonomía técnica frente al sector estatal:

"Durante los cuatro meses que mediaron entre los dos acuerdos del Consejo de la CORFO se produjo una delicada situación con el Poder ejecutivo, a raíz del proyecto de ley que había enviado a la Cámara de Diputados proponiendo crear una empresa eléctrica estatal, sobre el cual la CORFO manifestó su oposición. Endesa sería, entonces, su directa respuesta a la

\footnotetext{
${ }^{17}$ Congreso Nacional de Chile, Cámara de Senadores. 1939. Sesiones extraordinarias, 30 de marzo de 1939, Santiago, p. 489.

18 Bernedo, Patricio. 1989. "Prosperidad económica bajo Carlos Ibáñez del Campo, 1927-1929: la dimensión internacional de un programa económico de gobierno" en Historia, 5, pp. 5-105.

19 Drake, Paul. 1984. "La misión Kemmerer a Chile: consejeros norteamericanos, estabilización y endeudamiento, 1925 - 1932" en Cuadernos de historia, 4, pp. 31-59.

${ }^{20}$ Banco Central de Chile. 1932. Memoria anual, Santiago.

${ }^{21}$ Casanova, Mauricio. 2018. Los orígenes del desarrollismo económico en Chile (1932-1945): ¿Estado empresario o empresarios en el Estado?, Freie Universität Berlin, Tesis para optar al grado de doctor; Casanova, Mauricio. 2019. "La centro-izquierda, el corporativismo empresarial".
} 
iniciativa del gobierno y un compromiso que habría surgido para aliviar la tensión existente. La empresa fue creada como sociedad anónima; es decir, se constituyó una persona jurídica de derecho privado, aunque la propiedad de sus acciones correspondía a la CORFO. Este marco jurídico reforzaba la actitud de la Corporación de velar celosamente por su autonomía técnica frente al sector estatal tradicional, al cual veía demasiado contaminado por las influencias partidistas" 22 .

Lo que efectivamente reforzaba el carácter estatal de estas entidades encargadas de la política económica, en especial de la CORFO, era su financiamiento. La CORFO estaba financiada esencialmente con préstamos externos, los que eran pagados con recursos provenientes del impuesto a las ganancias de empresas extractoras de cobre en Chile; en conjunto con otros impuestos menores excepcionales ${ }^{23}$. Luego, desde 1948 , se comienza a incluir los fondos públicos de la corporación en las leyes de presupuesto. Tanto en la historia como en las ciencias sociales existe confusión con respecto a este punto. Se tiende a asociar financiamiento estatal con administración estatal; lo que no es válido para el caso de Chile. Los economistas, por ejemplo, deducen que este periodo estuvo caracterizo por la intervención estatal usando como argumento estadísticas de inversiones (como porcentaje del PIB) de entidades consideradas previamente como públicas ${ }^{24}$. Pero, en términos históricos, esto no quiere decir que dichas entidades hayan sido gestionadas en su totalidad por actores estatales y que, por ende, pueda hablarse intervención estatal. Financiamiento no es sinónimo de administración. De hecho, la incidencia de la CORFO en las compañías en las que era accionista mayoritario era solamente simbólica; como fue manifestado por el mismo presidente de la república:

"La atenta lectura que ha hecho de la carta de S.E. [Juan Antonio Ríos, presidente de la república (1942-1946)], y su contexto lógico, me ha convencido de que S.E. resuelve esta vieja cuestión, que es la más importante, a mi juicio, de las que ha preocupado a este interesante organismo, en el sentido primero, esto es que la Corporación debe hacer su ayuda a los productores solo por medio de préstamos, sin que el capital estatal alcance condiciones de codueño de la industrial”25.

\footnotetext{
22 Empresa Nacional de Electricidad. 1993. 50 años, Santiago, p. 37.

${ }^{23}$ Fermandois, Joaquin; Bustos, Jimena; Schneuer, María. 2009. Historia política del Cobre en Chile, Santiago, Centro de Estudios Bicentenario.

${ }^{24}$ Mamalakis, Markos. 1976. The growth and structure of the Chilean economy: from independence to Allende, New Haven, Yale University Press; Meller, Patricio. 1998. Un siglo de economía política chilena (1890-1990, Santiago, Universidad Andrés Bello.

${ }^{25}$ Roger, Jorge. 1945. "La Corporación de Fomento y la economía del futuro". Exposición leída en el consejo de la Corporación del día 25 de septiembre de 1944. Santiago, p. 12.
} 


\section{El Estado social des-financiado y el Banco Central como prestamista del fisco}

Otro aspecto que también genera confusión es la relación entre el financiamiento de las políticas de industrialización con otras áreas del gasto público. En general, se tiende a considerar que durante los gobiernos radicales o bajo el modelo desarrollista, el Estado ocupa un rol central tanto en el fomento de la economía como en las políticas sociales ${ }^{26}$. No obstante, tanto la administración como el financiamiento de las políticas ISI era diferente con respecto a las políticas sociales. El denominado Estado empresarial no contaba con los mismos recursos ni era gestionado de igual forma que el Estado social.

En primer lugar, para la implementación de políticas sociales no se contaba con organismos de carácter corporativo, como la CORFO o la Caja de Crédito Agrario. Estas eran propuestas por el poder ejecutivo, el que tuvo que enfrentar constantemente el bloqueo de la derecha en el parlamento, así como también los constantes obstáculos de las voces del empresariado. En las discusiones en torno al proyecto que crea la CORFO, las protestas del partido conservador dirigidas al supuesto carácter anticonstitucional de la corporación fueron tomadas en cuenta, incluyendo en los estatutos que la CORFO sería estructurada como "persona jurídica encargada de proponer al presidente de la República uno o varios proyectos de ley que contemplen el plan de fomento a la producción nacional”27. Sin embargo, no existen antecedentes históricos de algún proyecto de la CORFO que haya tenido que enfrentar la oposición del gobierno de turno o del poder legislativo. Existía un entendimiento tácito que la corporación tenía el derecho de actuar autónomamente debido a que supuestamente era administrada por un grupo equilibrado de poderes. Lo que sí existe, son instancias en donde el poder ejecutivo tuvo que enfrentar la oposición de la CORFO al momento de plantear un proyecto, como sucedió con la creación de Endesa. Las políticas sociales, propuestas por los gobiernos de turno, no contaban con este grado de autonomía, ya sea legal o tácita. Por este motivo, la asignación de recursos era una tarea política bastante difícil.

La CORFO, en cambio, estaba autorizada para negociar empréstitos extranjeros con garantía estatal, los que eran retribuidos con recursos provenientes del cobre. En las negociaciones de la corporación con el Export and Import Bank de Washington (Eximbank), uno de los principales acreedores, se estableció - por una condición impuesta por el mismo banco estadounidense que se creara una nueva ley que garantizara que los recursos públicos en dólares serían utilizados para el pago de los empréstitos. Tras los acuerdos de Bretton Woods en 1944, el dólar estadounidense se había consolidado como referente dentro de un sistema de tipos de cambio

\footnotetext{
${ }^{26}$ Moulian, Tomás. 1981. Desarrollo político y estado de compromiso; Garreton, Manuel. 1983. El proceso politico chileno; Montero, Cecilia. 1997. La revolución empresarial chilena; Gárate, Manuel. 2014. La revolución capitalista de Chile.

27 En Muñoz, Oscar y Arriagada, Ana María. 1977. Los orígenes políticos y económicos, p. 35.
} 
fijos $^{28}$. Por este motivo, el pago a los acreedores de la CORFO debía realizarse con recursos públicos en dólares u oro. La condición del Eximbank se hace realidad mediante la ley $7.046^{29}$, en septiembre de 1941, en la que se establece la garantía estatal de los empréstitos que, de forma autónoma, podía negociar la corporación. La consecuencia indirecta de estas medidas fue que los recursos provenientes del cobre, que comenzaban a transformarse en la principal fuente de los recursos del fisco, se reservaran para los programas de una corporación que, en la práctica, no estaba gestionada por actores estatales. Además, se impidió que estos recursos pudiesen ser utilizados en otras sub-áreas del gasto público, como el de las políticas sociales ${ }^{30}$.

Por este motivo, fue común que al cerrar cada año fiscal se tuviese que re-programar el financiamiento de las diversas reformas sociales que los gobiernos de turno intentaban implementar. Contrariamente a la visión a largo plazo, las políticas sociales tuvieron que restringirse a un contexto marcado tanto por el perpetuo des-financiamiento como por las medidas a corto-plazo. Además, en muchos casos, las reformas se contradecían entre sí.

Dos ejemplos son representativos de esta situación. En la ley 10.343 (mayo de 1952) ${ }^{31}$, en la que se reorganizaron los sueldos del sector público (que incluía a militares, personal de la salud, trabajadores de los ferrocarriles del Estado, personal de la educación, entre otros), se estableció que los montos para financiar el alza de los salarios se cubrirían con el rendimiento de la prórroga de impuestos establecidos en otra ley $(10.257 \text {, febrero de } 1952)^{32}$. A su vez, en esta segunda ley, se establecía una prorroga hasta el 31 de diciembre a una serie de impuestos a la renta o a la internación de mercancías. Es decir, que el financiamiento del alza de los salarios al sector público era efectivo solamente por dos años. Estas medidas a corto plazo habían comenzado en 1944 (ley 7.750$)^{33}$ y mediante diversas leyes $(8.404,8.920 \text {, por ejemplo })^{34}$ se habían extendido hasta principios de la década de 1950. Otro ejemplo es la creación del Fondo para la construcción y dotación de establecimientos de la Educación Pública (ley 11.766) ${ }^{35}$. Esta reforma fue financiada con una serie de impuestos en los que se incluían recargos a los sueldos imponibles para los efectos de las leyes de previsión o a los sueldos de empleados u obreros particulares y municipales. Por tanto, se contradecían los objetivos de otras leyes anteriores, como la $10.257^{36}$, en las que se buscaba precisamente lo contrario: aumentar el ingreso de los trabajadores del

\footnotetext{
28 Bordo, Michael y Eichengreen, Barry. 1993. A Retrospective on the Bretton Woods system, Chicago, Chicago University Press.

${ }^{29}$ Diario oficial de la República de Chile. 1941. Ley 7046 publicada el 22 de septiembre de 1941.

${ }^{30}$ Casanova, Mauricio. 2019. Los orígenes del desarrollismo económico en Chile (1932-1945), pp. 147-219.

31 Diario oficial de la República de Chile. 1952. Ley 10343, publicada el 22 de mayo de 1952.

32 Diario oficial de la República de Chile. 1952. Ley 10257, publicada el 12 de febrero de 1952.

33 Diario oficial de la República de Chile. 1944. Ley 7750, publicada el 7 de enero de 1944.

34 Diario oficial de la República de Chile. 1945. Ley 8404, publicada el 29 de diciembre de 1945; Diario oficial de la República de Chile. 1947. Ley 8920, publicada el 20 de noviembre de 1947.

35 Diario oficial de la República de Chile. 1954. Ley 11766, publicada el 30 de diciembre de 1954.

${ }^{36}$ Diario oficial de la República de Chile. Ley 10257, publicada el 11 de febrero de 1952.
} 
sector público. La facultad para poder realizar estas prórrogas tributarias había sido establecida años atrás, en 1942, en una ley que indicaba lo siguiente: “Facúltese al Presidente de la República para fijar y modificar las fechas de pago de los diversos impuestos y contribuciones fiscales y municipales y para establecer los procedimiento administrativos que juzgue más adecuados a su expedita y correcta percepción" ${ }^{37}$.

Esta situación fue frecuente durante el periodo. Cada año fiscal se establecían nuevos impuestos a corto plazo, los que - considerando las altas tasas de inflación - resultaban ser insuficientes en la mayor parte de los casos. La situación de las políticas de industrialización era considerablemente diferente. Los proyectos de la CORFO rara vez fueron cuestionados por los gobiernos de turno o por el parlamento, mientras que sus fondos eran permanentes y en divisas, por lo que no sufrían las consecuencias de la devaluación de la moneda local.

Por estos motivos, los gobiernos radicales, sobre todo a comienzos de la década de 1950, tuvieron que recurrir a un recurso considerado como mal menor: los préstamos del Banco Central al sector público. Desde la década de 1930, el Banco venía operando como prestamista en el contexto de la recuperación post-crisis. En junio de 1931, mediante la ley $4.971^{38}$, el Banco fue forzado a comprar bonos de deuda de la Compañía de Salitre de Chile (COSACH) con el objetivo supuestamente de reactivar la producción salitrera. En la práctica, esto significaba que el fisco podía contar con el porcentaje que le correspondía de los recursos de la COSACH y considerar las emisiones del Banco como si fuesen ingresos fiscales. En 1932, el Banco fue forzado también a emitir para adquirir vales del tesoro y a otorgar préstamos directos al fisco. Del total de emisiones adicionales del Banco en el periodo 1930-1932, 36\% correspondían a la compra de bonos de la $\mathrm{COSACH}, 32 \%$ a la adquisición de vales del tesoro y $15 \%$ a préstamos directos al fisco ${ }^{39}$. Solamente un $14 \%$ de las emisiones adicionales fueron utilizadas para financiar a los institutos semi-fiscales de crédito como la Caja de Crédito Agrario o el Instituto de Crédito Industrial. Para las autoridades de la República Socialista, era preferible crear instituciones controladas directamente por agentes del Estado antes que financiar institutos semi-fiscales. Los préstamos del Banco al fisco llegaron a representar cerca del $84 \%$ del total de las operaciones en este periodo.

Cuando Alessandri Palma retorna al poder, a finales de 1932, la situación cambia. El financiamiento al sector privado mediante el Banco Central pasa a tomar un rol central, mientras que los préstamos al fisco son abandonados en su totalidad. De hecho, la primera ley promulgada durante el nuevo gobierno estuvo dirigida a organizar el proceso de disolución de la COSACH. Las nuevas autoridades del ejecutivo, en conjunto con los principales gremios empresariales, consideraban que las emisiones de circulante para financiar al sector privado (mediante los institutos de crédito) correspondían a emisiones orgánicas, es decir, emisiones motivadas por

\footnotetext{
${ }^{37}$ Diario oficial de la República de Chile. 1942. Ley 7200, publicada el 21 de julio de 1942.

38 Diario oficial de la República de Chile. 1931. Ley 4971, publicada el 30 de julio de 1931.

${ }^{39}$ Casanova, Mauricio. 2019. Los orígenes del desarrollismo económico en Chile (1932-1945), p. 61.
} 
necesidades legítimas del mercado ${ }^{40}$. El nuevo directorio del Banco, comandado por Guillermo Subercaseaux, se mostró a favor de la postura del gobierno, aseverando que: "el Gobierno ha manifestado, implícitamente, su intención de no recurrir más al crédito del Banco Central para financiar el Presupuesto, con lo que se ha creado una de las condiciones primordiales para el restablecimiento de un sano régimen monetario en el país"41.

De esta manera, a principios del gobierno de Alessandri, se crearon una serie de leyes que consolidaron al Banco Central como prestamista del sector privado. Esto no era un fenómeno netamente local. En varios otros países se implementaron medidas similares. En los Estados Unidos, por ejemplo, el Glass-Steagall Act de 1932 permitió a la Reserva Federal realizar préstamos para regular la economía ${ }^{42}$. En Alemania, en 1933, se creó la Mefo $\mathrm{GmbH}$, entidad formada por varias compañías industriales que no realizaba ninguna operación real de producción, pero que podía emitir billetes (Mefo bills) convertibles en el Reichsbank. Con esto, el Banco Central alemán se transformaba en prestamista de la reconstrucción de la industria pesada germana ${ }^{43}$.

Créditos que el Banco Central podía otorgar a los institutos de crédito 1933-1934 (pesos chilenos)

\begin{tabular}{|c|c|c|c|}
\hline & $\begin{array}{c}\text { Ley } 5.815 \text { del } \\
30.06 .1933\end{array}$ & $\begin{array}{c}\text { Ley 5.307 del } \\
25.11 .1933\end{array}$ & $\begin{array}{c}\text { Ley } 5.398 \\
\text { del } 14.02 .1934\end{array}$ \\
\hline A la Caja de Crédito Agrario & 40.000 .000 & 40.000 .000 & 40.000 .000 \\
\hline Al Instituto de Crédito Industrial & 25.000 .000 & 25.000 .000 & 22.000 .000 \\
\hline A la Caja de Crédito Minero & 65.000 .000 & 65.000 .000 & 65.000 .000 \\
\hline A la Caja de Fomento Carbonero & 10.000 .000 & 10.000 .000 & 10.000 .000 \\
\hline A la Caja de Colonización Agrícola & 20.000 .000 & 20.000 .000 & 20.000 .000 \\
\hline A la Compañía de Salitre de Chile (en \\
$\begin{array}{c}\text { liquidación) } \\
\text { Funte: Casano }\end{array}$ & 140.000 .000 & 290.000 .000 & 190.000 .000 \\
\hline
\end{tabular}

Fuente: Casanova, Mauricio. 2018. Los orígenes del desarrollismo económico, p. 63

En los últimos años del periodo de los gobiernos radicales, a comienzos la década de 1950, el déficit fiscal, la dificultades derivadas de la obstaculización parlamentaria y la imposibilidad legal de utilizar los recursos del cobre para financiar otras reformas que no fuesen las políticas ISI, forzaron a las autoridades a volver a recurrir a las emisiones del Banco Central; las que no eran utilizadas con este propósito desde los inicios de la década de 1930. A este tipo de práctica se le denominaba emisiones inorgánicas, es decir, emisiones motivadas no en necesidades del mercado, sino en un supuesto interés político. Pero, evidentemente, detrás de esta práctica se

\footnotetext{
40 Ibáñez, Adolfo. 1983. "Los ingenieros, el estado y la política en Chile. Del ministerio de fomento a la Corporación de Fomento de la Producción"; Ibáñez, Adolfo. 1994. "El liderazgo en los gremios empresariales y su contribución al desarrollo del Estado Moderno durante la década del treinta: el fomento a la producción y los antecedentes de CORFO".

${ }^{41}$ Banco Central de Chile. 1933. Memoria anual, p. 15.

42 Meltzer, Allan H. 2003. A History of the Federal Reserve I. 1913-1951, Chicago, University of Chicago Press.

${ }^{43}$ Kopper, Christopher. 2006. Hjalmar Schacht: Aufstieg und Fall von Hitlers mächtigstem Bankier, München, Hanser.
} 
encontraba el sinnumero de complicaciones que, contrariamente al caso de las políticas ISI, existían para financiar las reformas sociales.

Cuando asume el gobierno de Aguirre Cerda (1938-1941), el rol del Banco Central como prestamista del sector privado contaba ya con varios detractores, debido a las consecuencias inflacionistas que ocasionaba la emisión excesiva de circulante. En un principio fueron los mismos gremios empresariales, los que, en el contexto de la crisis, en 1932, había propuesto esta estrategia. Pocos años después, durante la Segunda Guerra Mundial, las propuestas empresariales dejaron de lado las emisiones orgánicas, argumentando la necesidad de contar con recursos directos del fisco para el fomento de la economía. La CORFO, de cierta manera, constituye la culminación de estas demandas ${ }^{44}$.

De esta manera, los préstamos del Banco Central, utilizados como estrategia para re-activar el sector privado luego de la crisis económica, luego desechados por sus consecuencias inflacionistas al momento de instaurarse la CORFO, pasan a formar parte de un mal menor de los gobiernos radicales, ofuscados por la permanente dis-financiación del Estado social. A pesar de estas evidencias, la literatura sigue refiriendose a un supuesto consenso desarrollista basado en un Estado activo e intervencionista tanto en las políticas ISI como en las políticas sociales. La realidad parece estár más cercana a un Estado divido, en el que coexistían dos sub-regímenes: uno administrado corporativamente y financiado con la deuda externa y los recursos del cobre, en que el peso de los gremios empresariales era preponderante; otro gestionado por los gobiernos de turno, obstaculizado parlamentariamente, des-financiado y que tuvo que recurrir a los préstamos del Banco Central para evitar la crisis fiscal.

Emisiones del Banco Central 1951-1954 (millones de pesos chilenos)

\begin{tabular}{|c|c|c|c|}
\hline & Fines de 1951 & Fines de 1954 & Variación \\
\hline Operaciones con el Fisco & 2.687 & 16.837 & 14.150 \\
\hline Con entidades oficiales & 3.666 & 3.558 & -108 \\
\hline Con el público & 2.180 & 3.365 & 1.185 \\
\hline De cambio & 618 & -870 & -1.488 \\
\hline Otras operaciones & -1802 & -1.888 & -86 \\
\hline Con instituciones bancarias & 3.569 & 11.889 & 8.320 \\
\hline Total & 10.918 & 32.891 & 21.973 \\
\hline
\end{tabular}

Fuente: Banco Central de Chile. 1955. Memoria anual, p. 63

En el periodo 1951-1954, de los 21.973 millones de pesos emitidos adicionalmente, 10.713 correspondían a créditos directos con el fisco. Estas operaciones, que representaban cerca del $80 \%$ de las colocaciones del Banco en 1954, no eran superiores al 8\% en 1945. La ley que autorizaba estos préstamos al fisco era la misma que permitía las prórrogas tributarias

44 Casanova, Mauricio. 2019. "La centro-izquierda, el corporativismo empresarial y las contradicciones internas del Estado desarrollista”, pp. 193-204. 
mencionadas en los párrafos anteriores (ley 7.200). Del total de las emisiones adicionales utilizadas para otorgar créditos al fisco, 7.400 millones fueron requeridos en el marco de esta ley, en la que se facultaba al presidente de la República:

"para contratar con la Caja Autónoma de Amortización de la Deuda Pública préstamos con cargo a impuestos por percibir. Dichos préstamos podrán contratarse por medio de letras de cambio que serán giradas por dicha Caja y aceptadas por el Tesorero General de la República, y se descontarán en el Banco Central de Chile, sin limitaciones legales. El interés que podrá cobrar el Banco Central por estos descuentos será de uno por ciento anual"45.

Según indica la misma entidad emisora, "el mayor volumen de gastos fiscales en el año indicado fue el resultado de la promulgación de diversas leyes, destinadas en gran parte al reajuste de remuneraciones, aprobadas sin financiamiento efectivo" ${ }^{\prime 6}$. Esta situación produjo en 1953 un déficit de cerca de 19.000 millones de pesos, equivalente a $40 \%$ del presupuesto fiscal de ese año. Incluso se tuvo que recurrir a un préstamo de 12.500 millones del Fondo Monetario Internacional para confrontar este problema. Por ende, en los inicios del segundo gobierno de Ibáñez del Campo (1952-1958), la situación no cambió. De hecho, la ley 11.474 de diciembre de $1953^{47}$, que volvía - como la ley 10.343 de diciembre de 1951 - a incrementar el ingreso de los trabajadores del sector público, fue financiada mediante créditos del Banco Central. En la ley, se aseveraba lo siguiente:

“Autorícese al Presidente de la República para descontar en el Banco Central de Chile a través de la Caja Autónoma de Amortización y previa aceptación del Tesorero General de la República, una letra hasta por un monto de $\$ 1.500 .000 .000$ por un plazo cuyo vencimiento no exceda del 31 de marzo de 1954" 48 .

En el caso de lbáñez, contrariamente a la tendencia de los gobiernos radicales, la ley contemplaba el uso de los recursos del cobre como medida para financiar el alza salarial. Pero este recurso sería utilizado solamente en el caso que el préstamo del Banco Central no fuese suficiente para financiar esta reforma. Además, solo se haría uso del sobreprecio del cobre producido y sin vender hasta fines de noviembre de 1953. No era, de ninguna manera, una estrategia a largo plazo para utilizar el cobre en políticas sociales. Era, en cambio, un método de prórroga, a corto plazo y que obedecía a la situación de permanente des-financiamiento del Estado social. La ley contemplaba lo siguiente:

\footnotetext{
45 Diario Oficial de la República de Chile. 1942. Ley 7200, publicada el 21 de julio de 1942.

${ }^{46}$ Banco Central de Chile. 1955. Memoria anual, p. 64

${ }^{47}$ Diario Oficial de la República de Chile. 1953. Ley 11474, publicada el 28 de diciembre de 1953.

${ }^{48}$ Diario Oficial de la República de Chile. 1942. Ley 7200, publicada el 21 de julio de 1942.
} 
“Para el servicio de esta obligación, el Fisco destinará los ingresos en moneda extranjera que perciba por concepto de impuesto a la renta y 80 por ciento del sobreprecio que obtenga con la venta del cobre proveniente de las empresas productos de la gran minería que se encuentra producido y sin vender al 30 de noviembre de $1953^{\prime \prime 4}$.

\section{Las consecuencias del des-financiamiento del Estado social}

Debido a esta tendencia de utilizar indirectamente las emisiones del Banco Central para contrastar el déficit del fisco, el ciclo inflacionario, que había logrado ser controlado durante la década de 1930 hasta finales de la Segunda Guerra Mundial, vuelve a agravarse. Durante 1953 existieron intentos para enfrentar esta problemática mediante la creación de una nueva ley orgánica del Banco Central ${ }^{50}$, en la que se facultaba a la entidad emisora para controlar ciertas operaciones del sector bancario privado. Pero, si bien se intentó hacer uso de esta medida, estableciendo limitaciones para controlar el excesivo aumento del circulante, el 11 de noviembre del mismo año estos intentos fueron dejados sin efecto a petición del mismo ministro de hacienda. Según el Banco "la inflación latente que deriva de los aumentos del poder de compra ya producidos y la inflación potencial que se oculta en el desajuste de las finanzas públicas, permiten prever una aceleración intensa del fenómeno" ${ }^{51}$.

Para los intelectuales de la época este fue un tema recurrente. Anibal Pinto, por ejemplo, afirmó que "la presencia y desarrollo de un proceso inflacionario de considerable persistencia e intensidad constituye, sin duda, uno de los perfiles dominantes de la evolución económica en el periodo [1930-1953] que estamos examinando" ${ }^{52}$. Ahumada, con un argumento similar, aseveró que:

"La inflación desenfrenada y sistemática, la falta de oportunidades para la gente que por razones familiares no nació con ellas, la diferencia exagerada entre ricos y pobres y tantas otras aflicciones menos trascendentes, pero también mortificantes, como el problema del transporte urbano, son sentidas muy a lo vivo en la propia carne de cada cual, pero sus causas no son comprendidas con claridad. Existe, pues, una conciencia nacional de que el país está en crisis y hay manifestaciones evidentes de ansiedad por encontrar soluciones, pero tanto la mayoría de las interpretaciones que circulan, respecto a su naturaleza y origen, como las recomendaciones que avanzan para resolverla, carecen de fundamentos objetivos. De la verdadera y profunda crisis de Chile, no se tiene conciencia clara" ${ }^{53}$.

\footnotetext{
49 Ídem.

50 Diario oficial de la República de Chile. 1953. Decreto con fuerza de ley 106, publicado el 28 de julio de 1953.

51 Banco Central de Chile. 1955. Memoria anual, p. 70.

52 Pinto, Pinto. 1959. Chile, un caso de desarrollo frustrado, Santiago, Editorial Universitaria, p. 189.

53 Ahumada, Jorge. 1958. En vez de la miseria, Santiago de Chile, Editorial del Pacífico S.A., p. 15.
} 
Efectivamente, como puede observarse en la siguiente tabla, el alza del costo de la vida alcanza niveles críticos a mediados de la década de 1950. En casi todos los rubros identificados por las estadísticas se experimenta un incremento cercano al $1000 \%$, en comparación con los inicios de la década de 1940 . Solo los precios de los productos exportados e importados muestran un alza levemente menor a esta cifra. Los rubros más afectados fueron el vestuario y la alimentación:

Índices de precios 1940, 1954 (1950=100)

\begin{tabular}{|l|r|r|r|}
\hline & 1940 & 1954 & Variación (\%) \\
\hline Costo de la vida (general) & 19,6 & 322,5 & $1545 \%$ \\
\hline Costo de la vida (alimentación) & 20,3 & 365,3 & $1700 \%$ \\
\hline Costo de la vida (habitación) & 30,4 & 187,3 & $516 \%$ \\
\hline Costo de la vida (vetuario) & 12,4 & 302,8 & $2342 \%$ \\
\hline Precios al por mayo (general) & 22,7 & 313 & $1279 \%$ \\
\hline Precios de productos importados & 21,9 & 231,5 & $957 \%$ \\
\hline Precios de productos exportados & 25 & 261,3 & $945 \%$ \\
\hline Precio metro cuadrado edificado & 19,5 & 294,3 & $1409 \%$ \\
\hline
\end{tabular}

Fuente: Corporación de Fomento de la Producción. 1957. Cuentas nacionales, Chile, Editorial del Pacífico.

La situación de los salarios es llamativa. Por un lado, como indican Rodríguez y Durán ${ }^{54}$, los ingresos de los trabajadores industriales, del sector construcción o del rubro de la energía muestran un alza importante durante el llamado periodo desarrollista. Esto debido al rol redistributivo del Estado y la presión política de los sindicatos u agrupaciones de trabajadores. De hecho, según Rodríguez, estos años constituyen una época caracterizada por la crisis de las oligarquías tradicionales y por la disminución de la desigualdad del ingreso:

"La caída de la desigualdad fue un resultado directo del nuevo modelo de desarrollo y las condiciones políticas que lo ambientaron. Por un lado, el marcado giro a la izquierda, expresado en los resultados electorales, el incremento de la sindicalización, e incluso en la nueva orientación ideológica de los sectores conservadores. Los gobiernos de centroizquierda de la década del 1940 combatieron la desigualdad por el expediente de ampliar y favorecer a los sectores medios, en particular a los empleados -que la legislación laboral distinguía de los obreros. Para ellos se creó, por ejemplo, un salario mínimo, que en esos años creció sistemáticamente por encima de la inflación" 55

\footnotetext{
54 Rodríguez, Javier. 2014. La economía política de la desigualdad de ingreso en Chile; Rodríguez Javier. 2013. "Economía política de la distribución del ingreso rural en Chile durante la decadencia de la Hacienda, 1935-1971" en Revista uruguaya de historia económica, 3, pp. 33-62; Durán, Gonzalo. 2018. "Desigualdad y salarios en perspectiva histórica, siglos XIX y XX".

${ }^{55}$ Rodríguez, Javier. 2014. La economía política de la desigualdad de ingreso en Chile, p. 259.
} 
Como se expone en la tabla siguiente, las estadísticas confirman esta interpretación, pero solamente para el caso de obreros industriales y de los sectores construcción y energía. Estos, junto con los trabajadores del sector público, fueron los más beneficiados con las leyes sociales creadas por los gobiernos de centro-izquierda a mediados de siglo. Sin embargo, el caso de los trabajadores agrícolas es diametralmente opuesto. Los ingresos reales de los obreros agrícolas permanentes se mantuvieron casi intactos, mientras que el de obreros agrícolas temporales y pequeños propietarios agrícolas incluso desciende.

Salarios por actividades de orígenes 1940, 1954

(valores reales en millones de pesos de 1950)

\begin{tabular}{|l|r|r|r|}
\hline & 1940 & 1954 & Variación (\%) \\
\hline Obreros agrícolas permanentes & $3.841,30$ & $3.891,90$ & $1,3 \%$ \\
\hline Obreros agrícolas temporales & 345,9 & 275,4 & $-20,4 \%$ \\
\hline Pequeños propietarios agrícolas & 334,7 & 266,7 & $-20,3 \%$ \\
\hline Empleados agrícolas & $1.282,70$ & $1.607,00$ & $25,3 \%$ \\
\hline Gran minería & $2.364,30$ & $1.806,90$ & $-23,6 \%$ \\
\hline Mediana y pequeña minería & $1.764,80$ & $1.922,10$ & $8,9 \%$ \\
\hline Industria & $4.283,20$ & $9.805,70$ & $128,9 \%$ \\
\hline Construcción & $1.056,60$ & 2092,2 & $98,0 \%$ \\
\hline Electricidad y gas & 161,70 & 211,7 & $30,9 \%$ \\
\hline Agua & 20,40 & 89,4 & $338,2 \%$ \\
\hline Comercio & 548,50 & 623,6 & $13,7 \%$ \\
\hline Transportes & $1.886,20$ & $2.260,10$ & $19,8 \%$ \\
\hline Comunicaciones & 15,30 & 19,4 & $26,8 \%$ \\
\hline Servicios gubernativos & 762,20 & $1.058,70$ & $38,9 \%$ \\
\hline
\end{tabular}

Fuente: Corporación de Fomento de la Producción. 1957. Cuentas nacionales, Chile, Editorial del Pacífico.

Las cifras de los salarios del sector agrícola dan cuenta de una realidad que ya había sido señalada por autoras como Tinsman y Valdés ${ }^{56}$ : que a mediados del siglo XX en ciertos sectores del valle central las condiciones de los trabajadores no eran suficientes para garantizar un estándar mínimo de subsistencia. Esta situación, según las autoras, habría impactado con mayor gravedad a mujeres y niños:

“Los campesinos luchaban por la más mínima supervivencia. Estos últimos empezaban a trabajar desde muy pequeños, tenían un promedio de esperanza de vida de cuarenta y cinco

\footnotetext{
${ }^{56}$ Valdés, Ximena. 2007. La vida en común: familia y vida privada en Chile y el medio rural en la segunda mitad del siglo $X X$, Santiago de Chile, LOM; Tinsman, Heidi. 2009. La tierra para el que la trabaja: género, sexualidad y movimientos campesinos en la reforma agraria chilena, Santiago de Chile, LOM.
} 
años, y sufrían una de las tasas más altas analfabetismo, desnutrición y mortalidad infantil de la nación" ${ }^{57}$.

Existen reportes contemporáneos de la Organización de las Naciones Unidas para la Alimentación y la Agricultura (FAO) y del Banco Central que confirman esta situación ${ }^{58}$. A pesar de esto, autores como Rodríguez sostienen que los trabajadores agrícolas no se habrían visto tan afectados por la inflación debido a que gran parte de su salario era realizado en especies no monetarias (alimento, abrigo, etc.). Sin embargo, otros autores, como Robles, argumentan que en el mundo agrícola de mediados de siglo se venía experimentando un marcado proceso de expansión del trabajo asalariado. Según el autor:

"Como consecuencia del proceso de proletarización, la composición del ingreso de los inquilinos cambió sustancialmente, siendo cada vez más importante el ingreso derivado de su condición de asalariados. A comienzos de la década de 1940, un tercio del ingreso provenía del salario y de las raciones de alimentos por días trabajados; en 1965, tal proporción había subido en promedio a la mitad. Por su parte, los llamados 'voluntarios' proporcionaban mano de obra a la empresa terrateniente recibiendo un salario por días trabajados; aunque trabajaban menos días que los inquilinos, eran una proporción creciente de la fuerza de trabajo hacendal. Asimismo, aumentó la proporción de 'afuerinos', asalariados que no residían en la hacienda y eran contratados en las temporadas de alta demanda de trabajo, como las cosechas" ${ }^{59}$.

Si esta tesis es cierta, entonces es difícil suponer que el mundo del trabajo en el valle central haya sido menos susceptible a los vaivenes de la inflación. Esta parece ser la razón tras los informes de la FAO o del Banco Central en los que se muestra que los estándares de vida en el campo venían disminuyendo significativamente desde principios del siglo.

Por lo tanto, si bien el modelo desarrollista, la presión sindical y los gobiernos de centroizquierda pudiesen haber sido la causa del incremento del estándar de vida de los trabajadores formales (obreros industriales, empleados públicos y trabajadores de los sectores energía y construcción), la situación no es la misma para el caso tanto de trabajadores informales urbanos como de los trabajadores del sector agrícola.

\footnotetext{
57 Tinsman, Heidi. 2009. La tierra para el que la trabaja, p. 30.

58 Sanz, Armando. 1957. La Organización de las Naciones Unidas para la Agricultura y la Alimentación (FAO) y su cooperación a la solución de los problemas económico sociales de Chile, Santiago, Universitaria; Banco Central de Chile. 1964. Problemas de la agricultura en Chile, Santiago.

${ }^{59}$ Robles, Claudio y Kay, Cristobal. "La transición del sistema de hacienda al capitalismo agrario en Chile Central" en Jaksic, Iván; Robles, Claudio; Estefane, Andrés (eds.). 2018. Historia política de Chile, 1810-2010. Tomo III. Problemas económicos, Santiago, Fondo de Cultura Económica, pp. 121-122.
} 
La mayor parte de los historiadores consideran que el sector agrícola habría estado marginado de las políticas ISI y de los avances del desarrollismo económico. Esta sería la razón tras esta situación dispar en los ingresos de los sectores industriales y agrícolas ${ }^{60}$. Sin embargo, en esta investigación hemos intentado argumentar que el financiamiento de las políticas ISI a través de la CORFO, el des-financiamiento del Estado social y la necesidad de recurrir a créditos del Banco Central provocaron un ciclo inflacionario que afectó considerablemente el ingreso de trabajadores agrícolas. Por tanto, la mano de obra agrícola no se encontraba aislada del proceso de industrialización. Antes bien, se vio afectada negativamente por este.

\section{Consideraciones finales}

Algunos enfoques teóricos recientes, en particular la denominada tesis de la economía de altos salarios de Allen, sugieren que existe una relación directa entre el costo de la mano de obra y el despegue industrial europeo a comienzos del siglo XIX. Los estándares de vida en la Inglaterra pre-industrial, según esta perspectiva, habrían sido más altos en comparación con el resto de Europa o con las principales economías del este asiático. Esto, a su vez, habría incentivado las innovaciones teconlógicas, en la medida en que habría hecho más rentable (en términos comparativos) el reemplazo de trabajo por capital.

El caso de la industrialización tardía en Chile parece ser marcademente opuesto. No existe una relación directa entre estándar de vida e industrialización. Si bien durante el periodo desarrollista los índices de alfabetización, escolarización o nutrición experimentan una evolución positiva, esto se debió exclusivamente a las políticas sociales, no al desenvolvimiento de la economía. Es decir, que podrían haberse llevado a cabo similares reformas sin necesariamente haber implementado un modelo de industrialización por sustitución de importaciones. De hecho, en este artículo hemos intentado mostrar que las consecuencias del financiamiento de las políticas de industrialización (des-financiamiento de las políticas sociales, necesidad de recurrir a créditos del Banco Central) terminaron por provocar un ciclo inflacionario que impactó negativamente el ingreso de los trabajadores agrícolas. Por tanto, podría sostenerse que, desde este punto de vista, la industrialización tuvo un impacto negativo en el estándar de vida de cierta parte de la población.

La tesis historioráfica que establece una relación directa entre el modelo desarrollista, las políticas de industrialización y la mejora en las condiciones de vida de la población puede ser aplicable al caso de obreros industriales, funcionarios públicos o trabajadores de los sectores construcción y energía. Pero, en el caso del resto de los trabajadores, sobre todo los del sector agrícola, la situación es diferente. Para estos, el ciclo inflacionario provocado indirectamente por el financiamiento de las políticas de industrialización trajo consigo un decrecimiento del ingreso

\footnotetext{
${ }^{60}$ Bauer, Arnold. 1994. La sociedad rural chilena: desde la conquista española a nuestros días, Santiago, Editorial Andrés Bello.
} 
y, como relatan varios autores, el recrudecimiento de una situación histórica marcada por la mortalidad infantil y la desnutrición.

\section{Bibliografía}

Ahumada, Jorge. 1958. En vez de la miseria, Santiago de Chile, Editorial del Pacífico S.A.

Allen, Robert; Bengtsso, Tommy; Dribe, Martin. 2005. Living Standards in the Past: New Perspectives on Well-Being in Asia and Europe. Oxford OUP Oxford.

Allen, Robert. 2009. The British industrial revolution in global perspective, Cambridge, Cambridge University Press.

Allen, Robert. 2011. Global Economic History: A Very Short Introduction, Oxford, OUP Oxford.

Banco Central de Chile. 1932, 1953, 1955. Memoria anual, Santiago.

Banco Central de Chile. 1964. Problemas de la agricultura en Chile, Santiago.

Bauer, Arnold. 1994. La sociedad rural chilena: desde la conquista española a nuestros días, Santiago, Editorial Andrés Bello.

Beckert, Sven y Sachsenmaier, Dominic (eds.). 2018. Global History, Globally: Research and Practice around the World, London, Bloomsbury Publishing.

Bernedo, Patricio. 1989. “Prosperidad económica bajo Carlos Ibáñez del Campo, 1927-1929: la dimensión internacional de un programa económico de gobierno" en Historia, 5, pp. 5-105.

Bordo, Michael y Eichengreen, Barry. 1993. A Retrospective on the Bretton Woods system, Chicago, Chicago University Press.

Broadberry, Stephen y Gupta, Bishnupriya. 2006. "The early modern great divergence: wages, prices and economic development in Europe and Asia, 1500-1800" en The Economic History Review 59, pp. 2-31.

Casanova, Mauricio. 2018. Los orígenes del desarrollismo económico en Chile (1932-1945): ¿Estado empresario o empresarios en el Estado?, Freie Universität Berlin, Tesis para optar al grado de doctor.

Casanova, Mauricio. 2019. "La centro-izquierda, el corporativismo empresarial y las contradicciones internas del Estado desarrollista en Chile, 1932-1954" en Izquierdas, 48, pp. 190-210.

Cavarozzi, Marcelo. 1977. The government and the industrial bourgeoisie in Chile, 1938-1964, University of California, Tesis para optar al grado de doctor.

Coclanis, Peter A. 2011. "Ten Years After: Reflections on Kenneth Pomeranz's The Great Divergence" en Historically Speaking 12, pp. 10-12

Corporación de Fomento de la Producción. 1957. Cuentas nacionales, Chile, Editorial del Pacífico.

David Clark, Timothy. 2013. The State and the Making of Capitalist Modernity in Chile, York University, Tesis para optar al grado de doctor.

Drake, Paul. 1984. "La misión Kemmerer a Chile: consejeros norteamericanos, estabilización y endeudamiento, 1925 - 1932" en Cuadernos de historia, 4, pp. 31-59.

Durán, Gonzalo. 2018. "Desigualdad y salarios en perspectiva histórica, siglos XIX y XX” en Jacksic, Iván; Robles, Claudio; Estefane, Andrés (eds.). Historia política de Chile, 1810-2010. Tomo III. Problemas económicos, Santiago de Chile, Fondo de Cultura Económica, pp. 239-278.

Empresa Nacional de Electricidad. 1993. 50 años, Santiago.

Fermandois, Joaquin; Bustos, Jimena; Schneuer, María. 2009. Historia política del Cobre en Chile, Santiago, Centro de Estudios Bicentenario.

Gárate, Manuel. 2014. La revolución capitalista de Chile: 1973-2003, Santiago de Chile, Universidad Alberto Hurtado.

Garreton, Manuel. 1983. El proceso politico chileno, Santiago de Chile, FLACSO.

Glahn, Richard von. 2016. The Economic History of China: From Antiquity to the Nineteenth Century, Cambridge, Cambridge University Press. 
Goldstone, Jack. 2008. Why Europe? The Rise of the West in World History 1500-1850 New York, McGrawHill Education.

Gupta, Bishnupriya y Ma, Debin. 2010. “Europe in an Asian mirror: The Great Divergence” en H. O’Rourke, Kevin y Broadberry, Stephen (eds.). The Cambridge Economic History of Modern Europe: Volume 1: 1700-1870, Cambridge, Cambridge University Press, pp. 264-285

Ibáñez, Adolfo. 1983. "Los ingenieros, el estado y la política en Chile. Del ministerio de fomento a la Corporación de Fomento de la Producción" en Historia, 18, pp. 45-102.

Ibáñez, Adolfo. 1994. "El liderazgo en los gremios empresariales y su contribución al desarrollo del Estado Moderno durante la década del treinta: el fomento a la producción y los antecedentes de CORFO" en Historia, 28, pp. 183-216.

Ibáñez, Adolfo. 2003. Herido en el ala: Estado, oligarquias, y subdesarrollo Chile 1924-1960, Santiago de Chile, Universidad Andrés Bello.

Kopper, Christopher. 2006. Hjalmar Schacht: Aufstieg und Fall von Hitlers mächtigstem Bankier, München, Hanser.

Mamalakis, Markos. 1976. The growth and structure of the Chilean economy: from independence to Allende, New Haven, Yale University Press.

Marks, Robert. 2007. The Origins of the Modern World: A Global and Ecological Narrative from the Fifteenth to the Twenty-first Century, United States, Rowman \& Littlefield Publishers.

Meller, Patricio. 1998. Un siglo de economía política chilena (1890-1990, Santiago, Universidad Andrés Bello.

Meltzer, Allan H. 2003. A History of the Federal Reserve I. 1913-1951, Chicago, University of Chicago Press. Middell, Matthias y Robinson, Philipp. 2016. "The Great Divergence Debate" en Comparativ, vol. 26 (3), pp. 7-24.

Montero, Cecilia. 1997. La revolución empresarial chilena, Santiago de Chile, CIEPLAN/Dolmen Ediciones.

Moulian, Tomás. 1981. Desarrollo político y estado de compromiso: desajustes y crisis estatal en Chile, Santiago, Corporación de Investigaciones Económicas para Latinoamericana.

Muñoz, Oscar y Arriagada, Ana María. 1977. Orígenes políticos y económicos del estado empresarial en Chile, Santiago, Corporación de Investigaciones Económicas para Latinoamérica.

Ortega, Luis. 1989. Corporación de Fomento de la Producción: 50 años de realizaciones 1939-1989, Santiago, USACH, Facultad de Humanidades, Dept. de Historia.

Ortega, Luis. 2018. "La economía política de la industrialización a través de un siglo", en Jacksic, Iván; Robles, Claudio; Estefane, Andrés (eds.). Historia política de Chile, 1810-2010. Tomo III. Problemas económicos (Santiago, 2018), pp. 141-170.

Perdue, Peter. 2009. China Marches West: The Qing Conquest of Central Eurasia, United States, Harvard University Press.

Pinto, Pinto. 1959. Chile, un caso de desarrollo frustrado, Santiago, Editorial Universitaria.

Pomeranz, Kenneth. 2000. The Great Divergence: China, Europe, and the Making of the Modern World Economy, New Jersey, Princeton University Press.

Prechtl, Susanne. 2016. "Ressourcen der Neuen Welt und englische Kohle als Schlüsselfaktoren westeuropäischer Dominanz: The Great Divergence von Kenneth Pomeranz", en Sebaldt, Martin; Friedel, Sabine; Fütterer, Andreas; Schmid, Sarah (eds.). Aufstieg und Fall westlicher Herrschaft: Zum Grundproblem globaler Politik im Spiegel moderner Klassiker, Wiesbaden, Springer Fachmedien Wiesbaden, pp. 97-118.

Rengifo, Francisca. 2017. "El Estado de seguridad social chileno y la institucionalización desigual del bienestar" en Jaksic, Iván y Rengifo, Francisca (eds.). Historia política de Chile, 1810-2010. Tomo II. Estado y sociedad, Santiago, Fondo de Cultura Económica, pp. 397-424. 
Rivero, Rodrigo. 2018. "El crecimiento de la fecundidad frente a la modernización económica y las políticas sociales, Chile 1930-1973" en Revista de Gestión Pública, VII, pp. 5-42.

Robles, Claudio y Kay, Cristobal. "La transición del sistema de hacienda al capitalismo agrario en Chile Central" en Jaksic, Iván; Robles, Claudio; Estefane, Andrés (eds.). 2018. Historia política de Chile, 1810 2010. Tomo III. Problemas económicos, Santiago, Fondo de Cultura Económica, pp. 107-142.

Rodríguez Javier. 2013. "Economía política de la distribución del ingreso rural en Chile durante la decadencia de la Hacienda, 1935-1971" en Revista uruguaya de historia económica, 3, pp. 33-62.

Rodríguez, Javier. 2014. La economía política de la desigualdad de ingreso en Chile: 1850-2009, Universidad de la República, Tesis para optar el grado de doctor.

Roger, Jorge. 1945. "La Corporación de Fomento y la economía del futuro". Exposición leída en el consejo de la Corporación del día 25 de septiembre de 1944. Santiago

Rosenthal, Jean-Laurentand y Wong, Roy Bin. 2011. Before and beyond divergence: the politics of economic change in China and Europe, Cambridge, Harvard University Press.

Sanz, Armando. 1957. La Organización de las Naciones Unidas para la Agricultura y la Alimentación (FAO) y su cooperación a la solución de los problemas económico sociales de Chile, Santiago, Universitaria.

Silva, Patricio. 2008. In the Name of Reason: Technocrats and Politics in Chile, Philadelphia, Pennsylvania State University Press.

Sociedad de Fomento Fabril. 1939. "El industrial".

Tinsman, Heidi. 2009. La tierra para el que la trabaja: género, sexualidad y movimientos campesinos en la reforma agraria chilena, Santiago de Chile, LOM.

Valdés, Ximena. 2007. La vida en común: familia y vida privada en Chile y el medio rural en la segunda mitad del siglo XX, Santiago de Chile, LOM.

Vergara, Ángela. 2017. “Estado, trabajo y trabajadores” en Jaksic, Iván y Rengifo, Francisca (eds.). Historia política de Chile, 1810-2010. Tomo II. Estado y sociedad, Santiago, Fondo de Cultura Económica, pp. 365-396.

Vries, Peer. 2010. "The California School and Beyond: How to Study the Great Divergence?" en History Compass 8, pp. 730-751. 